\title{
O EFEITO ESCOLA SOBRE O DESEMPENHO DOS ALUNOS NAS REGIÕES METROPOLITANAS BRASILEIRAS
}

\author{
Luiza de Queiroz da Costa Campos ${ }^{1}$ \\ Tatiane Almeida de Menezes ${ }^{2}$ \\ Carlos Frederico A. Uchôa ${ }^{3}$
}

RESUMO: O sistema escolar é um tema bastante evidenciado, tanto nos meios de comunicação como na literatura acadêmica, principalmente quando se trata de discussões sobre o investimento em educação. Isso traz à tona a necessidade de entender a importância da escola no que tange à sua influência na educação e, como resultado, no desempenho do aluno. O objetivo deste trabalho foi verificar a existência da importância da escola e mensurá-la através do intervalo do Efeito Escola. Para isso, foi utilizado o índice de desigualdade $L$ de Theil, e, através de sua decomposição, puderam ser encontrados os intervalos do Efeito Escola nas principais regiões metropolitanas brasileiras, que mostraram a significância da escola para o desempenho do aluno.

Palavras-chave: Desempenho. Efeito Escola. Prova Brasil. Regiões Metropolitanas. Índice L de Theil.

\footnotetext{
${ }^{1}$ Graduanda do curso de Economia - UFPE. Bolsista do PET-Economia UFPE. Email: luizaqcampos@ gmail.com

${ }^{2}$ Docente/pesquisador do Departamento de Economia - UFPE. Email: tatianedemenezes@gmail.com

${ }^{3}$ Docente/pesquisador do Departamento de Economia - UFBA. Email: uchoa@ufba.br
} 
ABSTRACT: The discussion about education has always drawn attention, even more when we talk about its investments. It is necessary, then, to understand the importance of school when we talk about its influence in education and, as result, in the student's grades. The objective of this paper is to verify the importance of school and measure it through the School Effect gap. The method of Theil-L decomposition was used to find the gaps in the most important metropolitan areas of Brazil, and was found significant importance of school to student's achievement.

Keywords: Metropolitan Areas. Prova Brasil. School Effect. Students Achievement. Theil-L.

\section{INTRODUÇÃO}

A escola, surgida desde a Grécia Antiga, tem a missão social de educar e é o órgão oficial de transmissão de conhecimentos através da educação, base tanto para o crescimento da sociedade como para o do próprio cidadão. Segundo Barbosa Filho e Pessoa (2006), a educação gera externalidades positivas para a sociedade que nem sempre são mensuráveis, e tem um impacto permanente em todas as atividades do indivíduo. Glaeser, Ponzetto e Shleifer (2006) asseveram, acrescentando que as pessoas com maior escolarização estão mais propensas a interagir mais com as outras, elevando os benefícios da participação civil.

Outros benefícios menos facilmente percebíveis da educação são apontados por Lochner e Moretti (2001), que explicam a queda da criminalidade através da educação. Ela inibe a entrada no crime através de três canais: eleva o custo de oportunidade do criminoso, afeta a recompensa financeira e psicológica dos benefícios do crime e altera as preferências dos agentes.

Um fator essencial tem sido acrescido aos estudos de educação: a qualidade da escola. Card e Krueger (1994) mostram que existe efeito da qualidade da escola sobre os ganhos futuros dos estudantes e que há associação entre o aumento de investimentos na escola e o aumento nos ganhos anuais dos alunos. Hanushek e Kimko (2000) também falam da qualidade da escola ao explanar que houve um explícito aumento de poder de explicação dos modelos ao incluir a qualidade do ensino em estudos sobre o crescimento econômico.

No Brasil, entretanto, ainda há uma comprovada defasagem no investimento na educação e no desempenho dos alunos. Ainda segundo Hanishek e Kimko (2000), 
países capazes de proporcionar bom ensino a muita gente ao mesmo tempo elevam rapidamente o padrão de sua força de trabalho. Quando uma população atinge alta capacidade de raciocínio e síntese, torna-se naturalmente mais produtiva e capaz de criar riquezas para o país. Nesse sentido, a posição do Brasil é desvantajosa. Faltam aos alunos habilidades cognitivas básicas e isso funciona como um freio de mão para o crescimento.

A literatura especializada afirma que a família é responsável pela parcela majoritária da performance do aluno, como mostraram Coleman (1966), Barros (2001), entre outros, em seus trabalhos. Soares (2004), de forma consoante à literatura, afirma que os fatores mais importantes para o desempenho são o aluno e seu contexto, mas é possível auxiliá-lo alterando estruturas escolas. Logo, a escola ainda é um instrumento que possibilita a transformação da educação e é necessário entender a sua influência para o desempenho dos alunos.

O presente trabalho tem por objetivo medir a importância da escola através do efeito escola. A metodologia consiste em empregar a decomposição do índice $L$ de Theil com a finalidade de separar o efeito do aluno do efeito da escola, na nota de desempenho alcançada pelo aluno na Prova Brasil 2007. Esse recurso vai possibilitar a descoberta de um intervalo que demonstra o percentual de participação da escola na nota do aluno.

Este trabalho está dividido em quatro seções, além desta introdução. Na seção seguinte, é realizada uma revisão da literatura referente ao efeito escola e aos escores da Prova Brasil. Na terceira seção, encontra-se a análise descritiva dos dados e da metodologia utilizada. Na quarta seção, são apresentados e discutidos os resultados obtidos. E na quinta, e última seção, tem-se as considerações finais.

\section{REFERENCIAL TEÓRICO}

\section{O EFEITO ESCOLA}

Segundo o Instituto Nacional de Estudos e Pesquisas Educacionais Anísio Teixerira (2011), o efeito escola é definido como "a parcela de responsabilidade exclusiva do estabelecimento de ensino no desempenho do aluno" e por isso trata-se de um tema de tão amplo estudo, dada sua 
importância para o desenvolvimento da educação. Na literatura, porém, a definição de efeito escola não é consensual.

Raudenbush e Willms (1995) definiram dois tipos de efeito escola. O efeito $A$ é o considerado pelos pais ao escolher a escola de seu filho, por se tratar do efeito individual das escolas. Ele é definido como a diferença entre o desempenho real do aluno e o desempenho esperado caso ele estudasse em uma escola típica. ${ }^{4} \mathrm{O}$ efeito $\mathrm{B}$ isola o efeito das práticas da escola e é uma medida de um grupo de escolas, sendo este o objeto de interesse de pesquisadores e formuladores de políticas públicas. Ele é definido pelos autores como a diferença entre o desempenho real do aluno e o desempenho esperado caso ele frequentasse uma escola com contexto idêntico, ou seja, a diferença entre o desempenho do aluno e o desempenho médio dos alunos do mesmo "bloco". ${ }^{5}$

Para Andrade e Soares (2008), o uso da expressão "efeito escola", no caso do efeito tipo B, traz uma compreensão errônea da medida. Eles defendiam o uso da nomenclatura "medida de heterogeneidade", à qual atribuem a definição de medida de quão diferentes são as escolas brasileiras em relação ao desempenho de seus alunos, considerando o coeficiente de correlação intraescolar como estimador da heterogeneidade das escolas. ${ }^{6}$

César e Soares (2001) acrescentam o conceito de "efeito de pares" que, conforme explicado por Goldstein (2001), diz que "as crianças também aprendem com seus colegas, e as características e realização de outros alunos na escola irão influenciar o desenvolvimento de cada criança em particular". Mas explicam que, apesar de frequentemente encontrado, este efeito não tem uma interpretação clara e direta.

Um sinônimo comumente utilizado para o efeito escola é o conceito de "escola eficaz", que Ferrão e Andrade (2002) definem como escola "em que os resultados escolares dos alunos vão além do que seria esperado ele atingir em qualquer outra escola, dado o seu nível socioeconômico-cultural e o conhecimento prévio." E nesse contexto eles encontram o intervalo do efeito escola para as macrorregiões do Brasil com os dados do Saeb de 1999 que seguem na tabela abaixo.

\footnotetext{
${ }^{4}$ Para a definição de escola típica, ou "typical school", ver Raudenbush e Willms (1995);

${ }^{5}$ Para a definição detalhada do efeito escola B, ver Raudenbush e Willms, 1995.

${ }^{6}$ Dado por $\rho=\frac{\sigma_{u_{e}}^{2}}{\sigma_{r}^{2}+\sigma_{u_{0}}^{2}}$ (ANDRADE E SOARES; 2008).
} 
Tabela 1 - Intervalo do efeito escola encontrado por Ferrão e Andrade com o Saeb-99

\begin{tabular}{c|c|c}
\hline \multirow{2}{*}{ Região } & Efeito-escola controlado & Efeito-escola \\
\hline SE & $12,1 \%$ & $35 \%$ \\
\hline NE & $17 \%$ & $29 \%$ \\
\hline CO & $11,9 \%$ & $27 \%$ \\
\hline NO & $9,5 \%$ & $21 \%$ \\
\hline Sul & $7,6 \%$ & $21 \%$ \\
\hline
\end{tabular}

Fonte: Ferrão e Andrade, 2002.

Também utilizando os dados do Saeb 1999, Felício e Fernandes (2005) investigaram o efeito escola no estado de São Paulo e encontraram o intervalo de $8,7 \%$ e $34,44 \%$ para Matemática e $0 \%$ e $28,4 \%$ para Língua Portuguesa. O estudo de Soares (2010), realizado para o estado de Pernambuco com dados do Saeb 2007, apresentou um intervalo do efeito escola entre 14\% e 35\% para Matemática e 20\% e 33\% para Língua Portuguesa, para a $4^{\text {a }}$ série do Ensino Fundamental.

\section{ESCALA DE PROFICIÊNCIA}

A qualidade do ensino está sendo avaliada no Brasil a partir de uma escala de proficiência que representa a construção de competências dos alunos em cada uma das séries analisadas na Prova Brasil e no Saeb. A escala de proficiência é única para cada disciplina e os resultados de uma mesma disciplina são comparáveis entre as séries. Ela é dividida em níveis de classificação de desempenho que são classificados em "Muito Crítico", "Crítico", "Intermediário", "Adequado" e "Avançado". ("UM BRASIL PARA AS CRIANÇAS" - NOTA TÉCNICA)

Tabela 2 - Escala das notas e níveis correspondentes às classificações da $4^{\mathrm{a}}$ série para Língua Portuguesa

\begin{tabular}{c|c|c}
\hline Intervalo de Notas & Níveis & Classificação \\
\hline $0-125$ & Nível 0 & Muito Crítico \\
\hline $125-150$ & Nível 1 & Crítico \\
\hline $150-175$ & Nível 2 & \multirow{2}{*}{ Intermediário } \\
\hline $175-200$ & Nível 3 & Adequado \\
\hline $200-250$ & Nível 4 & Nível 5 \\
\hline
\end{tabular}




\begin{tabular}{c|c|c}
\hline $300-350$ & Nível 6 & \multirow{2}{*}{ Avançado } \\
\hline $350-\ldots$ & Níveis 7 e 8 & \multirow{2}{*}{ Av } \\
\hline
\end{tabular}

Fonte: Elaboração própria com dados do texto “Um Brasil para as crianças - Nota Técnica".

Tabela 3 - Escala das notas e níveis correspondentes às classificações da $4^{\text {a }}$ série para Matemática

\begin{tabular}{c|c|c}
\hline Intervalo de Notas & Níveis & \multirow{2}{*}{ Classificação } \\
\hline $0-125$ & Nível 0 & Muito Crítico \\
\hline $125-150$ & Nível 1 & \multirow{2}{*}{ Crítico } \\
\hline $150-175$ & Nível 2 & \multirow{2}{*}{ Intermediário } \\
\hline $175-200$ & Nível 3 & \multirow{2}{*}{ Adequado } \\
\hline $200-250$ & Nível 4 & \multirow{2}{*}{ Avançado } \\
\hline $300-300$ & Nível 5 & Nível 6 \\
\hline $350-375$ & Nível 7 & \\
\hline $375-\ldots$ & Níveis 8, 9 e 10 &
\end{tabular}

Fonte: Elaboração própria com dados do texto “Um Brasil para as crianças - Nota Técnica".

Para cada nível, existe uma descrição das competências alcançadas pelos alunos ${ }^{7}$. Em Língua Portuguesa, os alunos do nível muito crítico não foram alfabetizados adequadamente e por isso não sabem ler e não conseguiram responder à prova. Os alunos no nível crítico leem apenas frases simples e de forma "truncada". No nível intermediário, os alunos já conseguem ler, mas de forma ainda inferior ao necessário no fim da $4^{\mathrm{a}}$ série. No nível adequado, os alunos já compreendem os textos. E no nível avançado, os alunos têm suas habilidades consolidadas e além do esperado para a série.

Em Matemática, no nível muito crítico, os alunos não identificam nenhuma operação básica nem sabem o significado geométrico de figuras simples. No nível crítico, eles identificam apenas uma operação e só conseguem nomear as figuras planas simples mais conhecidas. Os alunos do nível intermediário identificam até duas operações e algumas figuras geométricas. No nível adequado, são capazes de reconhecer e resolver as quatro operações básicas (soma, subtração, multiplicação e divisão) e conhecem características de figuras geométricas planas. Os alunos avançados

\footnotetext{
${ }^{7}$ A descrição completa da construção de competências por níveis está disponível no site do Inep. < http://www.inep.gov.br/> Acesso em 21 de Fevereiro de 2011.
} 
apresentam uma habilidade de interpretação de problemas matemáticos superior ao esperado na $4^{\text {a }}$ série. (INEP, 2003)

Gráfico 1 - Porcentagem de alunos por estágio de construção de habilidades da $4^{\mathrm{a}}$ série em Língua Portuguesa

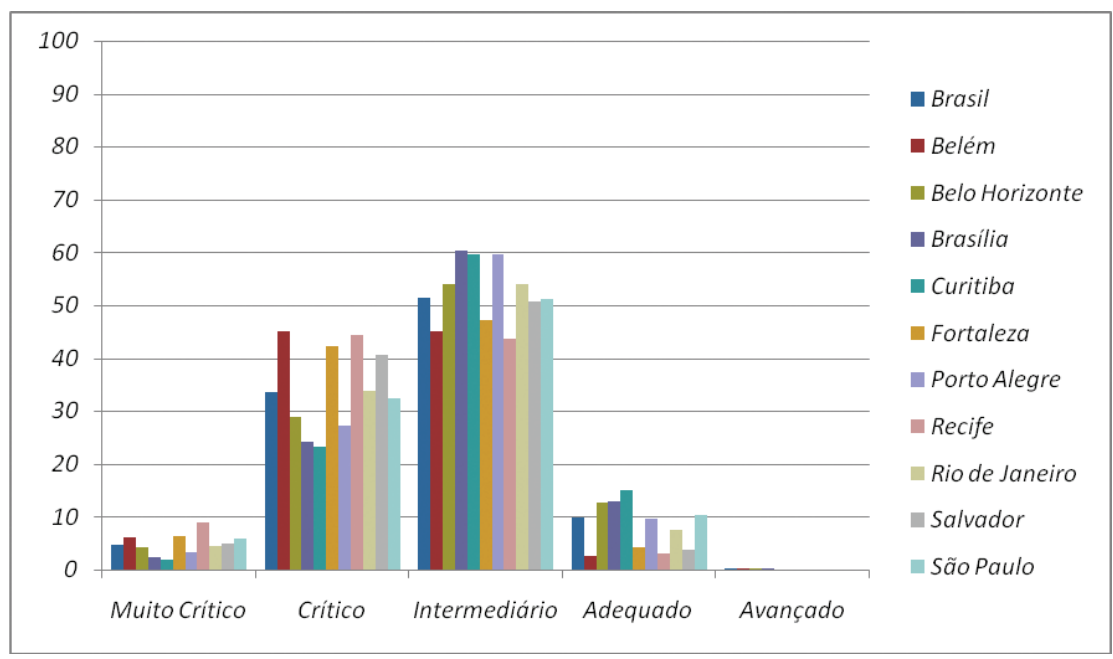

Fonte: Criação própria com dados da Prova Brasil 2007.

Gráfico 2 - Porcentagem de alunos por estágio de construção de habilidades da $4^{a}$ série em Matemática

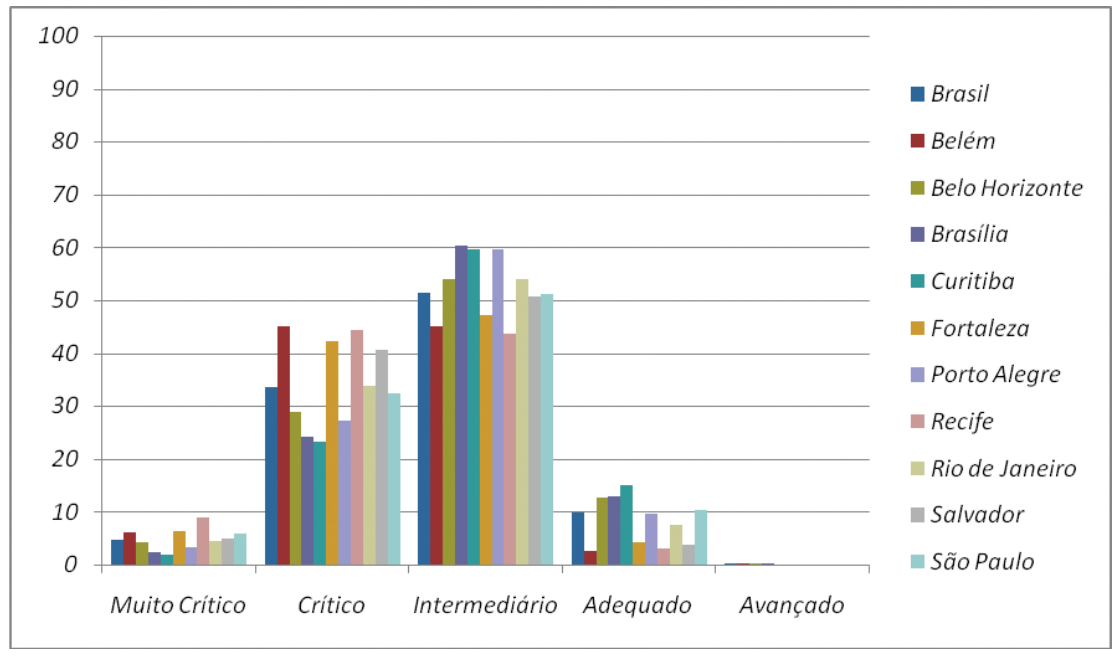

Fonte: Criação própria com dados da Prova Brasil 2007. 
Os gráficos anteriores mostram uma comparação da porcentagem de alunos do sistema público de ensino em cada um dos estágios de construção de competências em Língua Portuguesa e Matemática entre o Brasil e as regiões metropolitanas avaliadas neste trabalho para o ano de 2007. É interessante notar que existe uma tendência de comportamento entre os dados, em que a porcentagem se assemelha em todos os estágios.

No Gráfico 1, de Língua Portuguesa, Recife aparece como a região com maior porcentagem de alunos no nível Muito Crítico, 18,97\%, e Curitiba, com o menor percentual de alunos nesse nível, 6,05\%. Destacam-se, também, Belém, Fortaleza, Recife e Salvador como as regiões metropolitanas com maior quantidade de alunos no nível Crítico - 50,80\%, $48,59 \%, 49,25 \%$ e $48 \%$ respectivamente. No estágio Intermediário, há uma inversão: Recife dessa vez aparece com o menor número (30,53\%), enquanto Curitiba aparece com o maior (53,59\%). O nível Adequado mostra quantidades extremamente preocupantes de alunos, apresentando um intervalo de $1,04 \%$ a 5,36\% apenas de alunos no estágio Adequado de construção de competências da $4^{\mathrm{a}}$ série - correspondendo a Belém e Belo Horizonte, respectivamente.

No Gráfico 2, de Matemática, há uma repetição no estágio Muito Crítico do que foi encontrado no Gráfico 1, mostrando Recife $(8,86 \%)$ e Curitiba (1,93\%) nas mesmas posições. No nível Crítico aparece um espaço curioso entre Salvador e Rio de Janeiro que separa os com maior porcentual (Belém - 45,06\%, Recife - 44,40\%, Fortaleza - 42,35\% e Salvador-40,61) dos com menor (Rio de Janeiro - 33,72 até Curitiba - 23,32). O estágio Intermediário traz uma interessante inversão de quantidade e apresenta um pico substancialmente maior do que em Língua Portuguesa, em que Recife aparece com o menor percentual $(43,73)$ e Brasília com o maior $(60,27)$. O nível Adequado continua trazendo informações preocupantes, mas com uma pequena melhora, o intervalo passa a ser de 2,5\% a 15,07\% (Belém e Curitiba, respectivamente).

Em ambos os casos, o estágio Avançado aparece quase sem representação, não passando de 1\% em nenhum momento. Essa comparação mostra a realidade da educação brasileira no ano de 2007 e expõe a existência um problema generalizado em relação ao alcance dos objetivos da educação.

\section{METODOLOGIA E DESCRIÇÃO DOS DADOS}

A Prova Brasil faz parte de um sistema de avaliações para diagnóstico da educação desenvolvido pelo Inep/MEC ${ }^{8}$ que tem por objetivos tanto

${ }^{8}$ Instituto Nacional de Estudos e Pesquisas Educacionais Anísio Teixeira/Ministério da Educação 
a avaliação da qualidade do ensino oferecido pelo sistema educacional brasileiro como o incentivo ao desenvolvimento de uma cultura de avaliação no Brasil. A partir dos resultados, as instituições responsáveis pela educação no país podem definir, corrigir e direcionar os seus investimentos e a sociedade pode acompanhar e cobrar resultados.

Esta metodologia avalia os alunos de $4^{\mathrm{a}}$ e $8^{\mathrm{a}}$ séries do Ensino Fundamental da rede pública e urbana de ensino com pelo menos 20 alunos por série, sendo uma prova de caráter universal e censitário. As disciplinas avaliadas são Matemática e Língua Portuguesa, e, além disso, são respondidos questionários socioeconômicos pelos alunos, professores, diretores e escolas, complementando as informações geradas pelos testes.

Os resultados avaliam o desempenho e a construção de habilidades do conjunto de alunos e segue a metodologia de Teoria de Resposta ao Item (TRI), que permite a comparação ao longo do tempo. Em 2007, foi realizada uma prova única para a Prova Brasil e o Saeb.

Os alunos da $4^{\mathrm{a}}$ série do Ensino Fundamental, por ser uma das séries iniciais de estudo, apresentam uma probabilidade menor de terem estudado em outras escolas do que alunos de outras séries, de forma que têm pouco background escolar, tornando os resultados mais condizentes com a realidade das escolas. (FELÍCIO; FERNANDES, 2005) Além disso, é o momento escolar que tem o maior efeito de longo prazo nos estudantes, por se tratar de uma série em que diversos conhecimentos básicos são formados.

Por fim, é uma série com um baixo nível de evasão. Corresponde a uma idade em que os alunos têm baixo custo de oportunidade em estarem na escola, por isso as salas de $4^{\text {a }}$ série possuem uma alta frequência. Segundo dados da organização Todos Pela Educação, em 2007, a taxa de abandono dos anos iniciais do Ensino Fundamental foi de 3,2\% contra $6,7 \%$ dos anos finais e 13,2\% do Ensino Médio.

\section{ESTRATÉGIA DE ESTIMAÇÃO}

Felício e Fernandes (2005) percorrem o caminho contrário ao comum na literatura ao encontrar o efeito escola através da identificação e separação do efeito do aluno e não através das características da escola.

$O$ presente trabalho inova em relação à metodologia proposta ao aplicá-la nas 10 regiões metropolitanas mais populosas do Brasil: Belém, Belo Horizonte, Brasília, Curitiba, Fortaleza, Porto Alegre, Recife, Rio de Janeiro, Salvador e São Paulo.

O método consiste em aplicar a decomposição do índice de Theil, na tentativa de identificar quanto desigualdade em educação pode ser 
explicada pelas características dos alunos (desigualdade intraescolas). E quanto é explicada pela desigualdade entre as escolas (entre escolas). O índice de Theil é uma medida de desigualdade comumente utilizada para a distribuição de renda, mas nesse caso se adequa à desigualdade na distribuição das notas dos alunos.

Optou-se por empregar o índice $L$ de Theil ao invés do T de Theil, por se tratar de uma medida em que os fatores de ponderação da desigualdade dentro dos grupos são as populações dos grupos, tornando o seu resultado mais preciso. (HOFFMAN, 1998)

A decomposição do índice $L$ de Theil é representada pela equação abaixo

$$
L=L_{\theta}+\sum_{\boldsymbol{h}=1}^{k} \pi_{h} L_{\boldsymbol{h}}
$$

em que Le representa a desigualdade intergrupo (denominada desigualdade de notas entre escolas por Felício e Fernandes (2005), Lh, a desigualdade intragrupo (desigualdade de notas intraescolas) e a razão entre a quantidade de alunos da escola e a quantidade de alunos da amostra. $\left(\pi_{h}=\frac{n_{h}}{N}\right)$.

Da fórmula do índice $L$ de Theil, é retirado que

$$
\begin{gathered}
L_{\theta}=\sum_{h} \pi_{h} \log \left(\frac{\pi_{h}}{Y_{h}}\right) \\
L_{h}=\left(\frac{1}{n_{h}}\right) \sum_{i} \log \left(\frac{Y_{h}}{n_{h} Y_{h i}}\right)
\end{gathered}
$$

que representam respectivamente a desigualdade entre escolas e intra-escolas, em que $Y h$ é a razão entre somatório das notas da escola $h$ e o somatório das notas da amostra, e Yhi é a a razão entre a nota do indivíduo $i$ pelo somatório das notas da amostra.

A importância da separação dessas parcelas acontece porque a segunda ( $L h$ ou desigualdade intraescolas) não se relaciona com os atributos escolares e não será atingida por políticas educacionais. Entretanto, o Le é uma superestimação do efeito escola, por incluir fatores não relacionados exclusivamente à escola. (FELÍCIO; FERNANDES, 2005)

Isso pode ser explicado de forma simples: alunos com o background familiar e níveis socioeconômicos semelhantes tendem a estar nas mesmas escolas, o que eleva a média das escolas com alunos com melhor 
background e diminui a média das escolas com alunos com background mais baixo, independente da qualidade da escola. O Le encontrado, na realidade, é o limite superior do efeito escola, ou seja, o efeito superestimado (máximo) da escola sobre o desempenho dos alunos.

Em outras palavras, a alocação de alunos nas escolas não é aleatória e o nível social das famílias contribui na escolha da escola que o aluno irá frequentar. (FERRÃO; ANDRADE, 2002) Assim, é necessário se realizar uma nova decomposição de Le, para separar o efeito do background familiar.

$$
L_{\theta}=\sum_{h} \pi_{h} \log \left(\frac{n_{h}}{N} \times \frac{\sum_{\mathrm{h}} \operatorname{Notas}_{\mathrm{h}}}{\sum_{i} \operatorname{Notas}_{\mathrm{hi}}}\right)=\sum_{\mathbf{h}} \pi_{\boldsymbol{h}} \log \left(\frac{\operatorname{Notas}^{M}}{\operatorname{Notas}_{h}^{M}}\right)
$$

em que Notas $^{\mathrm{M}}$ é a média das notas da amostra e Notash ${ }^{\mathrm{M}}$ é a média das notas da escola $h$. Como

$$
\operatorname{Notas}_{h}^{M}=\operatorname{Notas}^{M} \cdot X_{h} \cdot E_{h}
$$

em que $X h$ é o desvio da média devido às diferenças do background das famílias da escola $h$ e Eh é o desvio da média devido às diferenças entre as escola, encontra-se:

$$
L_{e}=\sum_{h} \pi_{h} \log \left(\frac{1}{X_{h}}\right)+\sum_{h} \pi_{h} \log \left(\frac{1}{E_{h}}\right)
$$

em que a primeira parcela é referente à Le explicada pelas diferenças das crianças $(L e X)$ e a segunda, à Le explicada pelas diferenças de qualidade das escolas $(L e E)$.

Estima-se uma Regressão Linear por Mínimos Quadrados Ordinários (MQO) para obter Xh e Eh:

$$
\ln \left(\operatorname{Notas}_{h}^{M}\right)=\phi+\left(W^{M}-W_{h}^{M}\right) \lambda+\mu
$$

em que $W^{\text {M }}$ é um vetor com as médias das características de background familiar, $\varphi$ é a constante, $\lambda$ é o vetor de coeficientes a serem estimados e $\mu$ é o termo de erro.

Verifica-se que $\varphi$ corresponde ao logaritmo natural da média geral de notas, $\left(W^{M}-W_{h}^{M}\right) \lambda$ é o logaritmo natural de Xh e $\mu$ é o logaritmo natural de $E$ h, confirmando a segunda decomposição de Le. 
Ainda segundo Felício e Fernandes (2005), as características que afetam o desempenho escolar relacionadas ao aluno devem ser expressas no vetor de características W para que $L e E$ não seja enviesado. E se elas forem correlacionadas às características da escola, $\lambda$ será superestimado e o efeito escola (LeE) será subestimado, por isso esse segundo efeito encontrado é considerado o limite inferior (mínimo) do efeito escola.

Resumindo, se existe correlação positiva entre o background familiar e dos alunos e a qualidade das escolas, será encontrado um intervalo [LeE, Le] em que Le é o limite superior e $L e E$, o limite inferior para o efeito escola.

\section{RESULTADOS}

A Tabela 4 apresenta os dados de média e índice $L$ de Theil para o Brasil e as suas grandes regiões (Norte, Nordeste, Centro-oeste, Sudeste e Sul) e foi criada com o objetivo de ser utilizada como comparação para as regiões metropolitanas trabalhadas.

Tabela 4 - Média e Theil L para o Brasil e suas macrorregiões para Língua Portuguesa e Matemática

\begin{tabular}{c|c|c|c|c}
\hline \multirow{2}{*}{ MACRORREGIÕES } & \multicolumn{2}{|c|}{ Português } & \multicolumn{2}{c}{ Matemática } \\
\cline { 2 - 5 } & Média & Theil L & Média & Theil L \\
\hline Brasil & $\mathbf{1 7 3 , 6 9}$ & $\mathbf{0 , 0 2 9}$ & $\mathbf{1 9 1 , 1 9}$ & $\mathbf{0 , 0 2 6}$ \\
\hline Norte & 163,81 & 0,025 & 178,50 & 0,021 \\
\hline Nordeste & 159,19 & 0,026 & 175,30 & 0,022 \\
\hline Centro-oeste & 176,59 & 0,025 & 193,19 & 0,023 \\
\hline Sudeste & 179,82 & 0,030 & 198,12 & 0,027 \\
\hline Sul & 182,16 & 0,022 & 201,28 & 0,022 \\
\hline
\end{tabular}

Fonte: Elaboração própria/Dados da Prova Brasil 2007.

Os dados mostram clara superioridade da região Sul em relação às demais, no que diz respeito às médias, em ambas as matérias. O Sul tem a maior média, sendo maior, inclusive, que a do Brasil e com uma diferença razoável da média do Brasil. Já o Nordeste aparece com a menor média nas duas disciplinas, com médias substancialmente menores que as do Brasil, apresentando um quadro preocupante.

Em relação ao Theil $\mathrm{L}$, há certa consistência nos resultados encontrados para as regiões e para o Brasil, sobressaindo apenas o Sudeste e o Brasil, que apresentam uma desigualdade maior que a das outras regiões, que variam entre 0,021 e 0,023 em Matemática e entre 0,022 e 0,026 em 
Língua Portuguesa, enquanto o Sudeste apresenta 0,027 e 0,030 e o Brasil com 0,026 e 0,029 (correspondentes, respectivamente, a Matemática e a Língua Portuguesa em ambos os casos).

Em relação às regiões metropolitanas, os resultados foram separados em duas tabelas, uma correspondente a Português e a outra, a Matemática. As tabelas abrangem a média para cada região metropolitana e o intervalo do efeito escola, indicado pelo Efeito Mínimo $(L e E)$ e pelo Efeito Máximo (Le) como limites mínimo e máximo, respectivamente.

Tabela 5 - Médias e intervalos dos efeitos escolas das regiões metropolitanas para Língua Portuguesa em 2007

\begin{tabular}{c|c|c|c}
\hline \multirow{2}{*}{$\begin{array}{c}\text { Regiões } \\
\text { Metropolitanas }\end{array}$} & \multirow{2}{*}{ Média } & \multicolumn{2}{|c}{ Intervalo do Efeito Escola } \\
\cline { 3 - 4 } & & Efeito Mínimo (LeE/L) & Efeito Máximo (Le/L) \\
\hline Belém & 162,21 & $3,26 \%$ & $7,49 \%$ \\
\hline Belo Horizonte & 178,31 & $0,00 \%$ & $16,21 \%$ \\
\hline Brasília & 184,91 & $0,00 \%$ & $15,12 \%$ \\
\hline Curitiba & 185,28 & $7,08 \%$ & $9,41 \%$ \\
\hline Fortaleza & 163,56 & $0,00 \%$ & $10,37 \%$ \\
\hline Porto Alegre & 178,81 & $3,48 \%$ & $11,29 \%$ \\
\hline Recife & 158,65 & $0,00 \%$ & $10,49 \%$ \\
\hline Rio de Janeiro & 173,89 & $6,39 \%$ & $11,84 \%$ \\
\hline Salvador & 167,13 & $0,00 \%$ & $8,84 \%$ \\
\hline São Paulo & 174,21 & $9,12 \%$ & $9,15 \%$ \\
\hline
\end{tabular}

Fonte: Elaboração própria/Dados da Prova Brasil 2007.

As médias em Língua Portuguesa apresentam de forma clara a problemática da educação no país. Nenhuma das regiões metropolitanas, em média, atingiu o nível adequado de construções de competências para a $4^{\mathrm{a}}$ série, que seria a nota 250, e, aliás, ficaram distantes dessa nota, uma vez que a região metropolitana com maior média, Curitiba, ficou com 185,28, muito aquém do apropriado - quase 65 pontos de diferença. Recife aparece novamente com a menor média, 158,65, se enquadrando no nível crítico e com uma diferença grande da segunda região metropolitana com menor média, Belém com 162, 21 - uma diferença de quase 4 pontos. Todas as regiões ficaram entre os níveis crítico e intermediário.

Em relação aos intervalos do efeito escola, São Paulo aparece de forma bastante homogênea, apresentando um intervalo com apenas 0,03 pontos percentuais de diferença. O maior intervalo encontra-se em Belo Horizonte, que apresentou uma diferença de 16,21 pontos percentuais, quando se controla pelo background do aluno. 
Os efeitos mínimos foram baixos, mas são subestimados e ainda assim demonstram uma parcela importante da importância da escola para o desempenho do aluno, principalmente para São Paulo e Curitiba, com uma influência na proficiência de 9,12\% e 7,08\%, respectivamente.

Tabela 6 - Médias e intervalos dos efeitos escolas das regiões metropolitanas para Matemática em 2007

\begin{tabular}{c|c|c|c}
\hline \multirow{2}{*}{$\begin{array}{c}\text { Regiões } \\
\text { Metropolitanas }\end{array}$} & \multirow{2}{*}{ Média } & \multicolumn{2}{|c}{ Intervalo do Efeito Escola } \\
\cline { 3 - 4 } & & Efeito Mínimo (LeE/L) & Efeito Máximo (Le/L) \\
\hline Belém & 176,11 & $0,22 \%$ & $6,28 \%$ \\
\hline Belo Horizonte & 197,18 & $0,57 \%$ & $15,65 \%$ \\
\hline Brasília & 202,19 & $0,00 \%$ & $15,20 \%$ \\
\hline Curitiba & 204,93 & $2,62 \%$ & $10,43 \%$ \\
\hline Fortaleza & 179,29 & $0,00 \%$ & $11,39 \%$ \\
\hline Porto Alegre & 196,42 & $0,00 \%$ & $11,93 \%$ \\
\hline Recife & 174,13 & $0,00 \%$ & $10,27 \%$ \\
\hline Rio de Janeiro & 189,30 & $4,73 \% \%$ & $11,84 \%$ \\
\hline Salvador & 181,03 & $0,00 \%$ & $8,44 \%$ \\
\hline São Paulo & 191,34 & $10,49 \%$ & $9,05 \%$ \\
\hline
\end{tabular}

Fonte - Elaboração própria/Dados da Prova Brasil 2007.

Para Matemática, as médias foram mais altas, mas nenhuma região conseguiu atingir o nível adequado, apesar de terem chegado mais perto do que para o caso de Língua Portuguesa. Recife novamente aparece com a pior média, 174,13, ainda no nível crítico, mas com um crescimento considerável em relação à média de Língua Portuguesa (cerca de 15 pontos a mais). Curitiba reaparece com a maior média, 204,93, com também considerável aumento em relação à disciplina anterior (quase 20 pontos a mais). Nessa matéria, apenas Recife se encontra no nível crítico, enquanto as outras regiões se localizam no nível intermediário.

Os intervalos, para Matemática, são em geral maiores do que para Língua Portuguesa, e quando houve diminuição, esta foi pouca. O maior intervalo ficou com Brasília, com uma diferença de 15,20 pontos percentuais entre seus extremos.

\section{CONCLUSÕES}

O presente trabalho que teve por objetivo medir a importância da escola através do efeito escola, mostrou que existe grande influência da escola na proficiência do aluno. Em alguns casos, a sua influência chegou a $16 \%$ da nota sendo explicada pela escola. 
Os resultados apresentaram efeitos escola com intervalos pequenos e efeitos mínimos razoáveis para as regiões metropolitanas. Entretanto, não foram saldos fora do esperado, pois existiram alguns fatores limitadores importantes no trabalho.

O primeiro deles foi tratar-se apenas das regiões metropolitanas, que, apesar de ser bastante interessante agregar municípios com características parecidas, o que intensificaria o funcionamento de políticas públicas nessas áreas, torna os dados mais homogêneos, interferindo no tamanho do intervalo.

O segundo foi a escolha do banco de dados. A Prova Brasil é um banco importante por tratar-se não de uma amostragem, mas de resultados universais que podem ser reconhecidos como retratos fiéis da realidade. Porém, ele avalia apenas as escolas públicas das áreas urbanas, criando um grupo demasiadamente homogêneo e apresentando efeitos escola baixos.

Contudo, é válido perceber que, apesar dessas dificuldades, os intervalos de efeito escola encontrados ainda correspondem a uma parte relevante do desempenho dos alunos, mostrando que a escola é importante.

Contribuições futuras seriam direcionadas no sentido de investigar a fundo que variáveis relacionadas às escolas foram significantes para a obtenção desses dados, apresentando mais uma informação a respeito do desenvolvimento do desempenho dos alunos.

Outro passo interessante a ser dado numa pesquisa futura seria a comparação dos resultados encontrados para as escolas públicas com resultados para escolas privadas, criando uma comparação respeitável para a ampliação do quadro sobre a realidade da educação no Brasil.

\section{REFERÊNCIAS}

ALBERNAZ, Â. FERREIRA, F. H. G. FRANCO, C. Qualidade e eqüidade na educação fundamental brasileira. Rio de Janeiro: 2002 (Texto para Discussão, 455).

ARAÚJO, C. H.; LUZIO, N. Avaliação da educação básica em busca da qualidade e eqüidade no Brasil. Brasília, DF: Instituto Nacional de Estudos e Pesquisas Educacionais Anísio Texeira, 2005.

ANDRADE, R.; J. de; SOARES, J. F. O efeito da escola básica brasileira. Estudos em Avaliação Educacional. v. 19, n. 41, set./dez. 2008.

BARBOSA, M. E. F.; FERNANDES, C. A escola brasileira faz diferença? Uma investigação dos efeitos da escola na proficiência em Matemática dos alunos da $4^{\mathrm{a}}$ série. in: FRANCO, C. Promoção, ciclos e avaliação educacional. Curitiba: ArtMed 2001. 
BARBOSA-FILHO, F.; PESSOA, S. Educação e crescimento: o que a evidência empírica e teórica mostram? Instituto Futuro Brasil, 2006 Mimeografado.

BARROS, R.; P. de et al. Determinantes do desempenho educacional no Brasil. Rio de Janeiro: IPEA, 2001. (Texto para Discussão, 834).

BARROS. R. P. de.; HENRIQUES, Ricardo; MENDONÇA, R. Pelo fim das décadas perdidas: educação e desenvolvimento sustentado no Brasil. Rio de Janeiro: IPEA 2002 (Texto para Discussão, 857).

BIONDI; R.; L.; FELÍCIO, F.; de. Atributos escolares e o desempenho dos estudantes: uma análise em painel dos dados do Saeb. Brasília, DF: INEP, 2007.

CARD, D.; KRUEGER, A.; B. Labor market effects of school quality: theory and evidence. NBER Working Paper Series, 1996. (Working Paper, 5450).

CARD, David; KRUEGER, Alan B.The Economic Return to School Quality: A Partial Survey. New Jersey: Princeton University, 1994 (Working Paper, 334).

CASTRO, C. de. Por que não deveríamos nos preocupar com a qualidade da educação. In: VELLOSO, J. P. dos R. (Coord.) A crise global e o novo papel mundial dos BRICS. Rio de Janeiro: J. Olímpio: Forum Nacional, 2009.

CÉSAR, C. C. SOARES, J. F. Desigualdades acadêmicas induzidas pelo contexto escolar. Revista Brasileira de Estudos de População, v. 18, n. 1/2, jan./dez. 2001.

COLEMAN, J. S. et al. Equality of Educational Opportunity, Washington, Office of Education, U.S. Department of Health, Education and Welfare, 1966.

FELÍCIO, F. de; FERNANDES, R. O efeito da qualidade da escola sobre o desempenho escolar: uma Avaliação do Ensino Fundamental no Estado de São Paulo. Anais do XXXIII Encontro Nacional de Economia, 2005.

FERRÃO, M. E.; ANDRADE, A. C. O sistema nacional de avaliaçãi da educação básica e a modelagem dos dados. Rio Estudos, n. 48, mar. 2002 (Coleção Estudos da Cidade)

FERRÃO, M. E.; BELTRÃO, K.; FERNANDES. C. Aprendendo sobre a escola eficaz: evidências do Saeb 1999. Brasília, DF: INEP/MEC, 2002.

FERRÃO, M. E. et al. O SAEB - Sistema Nacional de Avaliação da Educação Básica: objetivos, características e contribuições na investigação da escola eficaz. Revista Brasileira de Estudos de População, Rio de Janeiro, v. 18, n. 1/2, jan./dez. 2001. 
FRANCO, C. et al. O referencial teórico na construção dos questionários contextuais do Saeb 2001. Estudos em Avaliação Educacional, n. 28, jul./dez. 2003.

GLAESER, E. L., PONZETTO, G.; SHLEIFER, A. Why Does Democracy Need Education? NBER Working Paper Series, Vol.w12128, 2006.

HANUSHEK, E. A.; KIMKO, D. Schooling, Labor-Force Quality, and the Growth of Nations? The American Economic Review v. 5, n. 90, p. $1184-1208,2000$.

HOFFMAN, R. Distribuição de renda: medidas de desigualdade e pobreza. São Paulo: Edusp, 1998.

INSTITUTO NACIONAL DE ESTUDOS E PESQUISAS EDUCACIONAIS ANÍSIO TEIXEIRA. Qualidade da educação: uma nova leitura do desempenho dos estudantes da $4^{\text {a }}$ série do Ensino Fundamental. Abril, 2003.

INSTITUTO NACIONAL DE ESTUDOS E PESQUISAS EDUCACIONAIS ANÍSIO TEIXEIRA. 2011. Disponível em: <www.inep.gov.br > . Acesso em: fev. 2011.

LOCHNER, L; MORETTI, E. The Effect of Education on Crime: Evidence From Prison Inmates, Arrests and Self-Reports, NBER Working Paper Series 8605, 2001.

MENEZES FILHO, N. Os determinantes do desempenho escolar do Brasil. São Paulo: Instituto Futuro Brasil: Ibmec-SP: FEA-USP, 2007.

RAUDENBUSH, S. W.; WILLMS, J. Douglas. The estimation of School Effects. Journal of Education and Behavioral Statistics, V. 20, n. 4, p. 307-335, 1995.

SOARES, J. F. O efeito da escola no desempenho cognitivo de seus alunos. REICE - Revista Electrónica Iberoamericana sobre Calidad, Eficacia y Cambio en Educación, v. 2, n. 2, dez. 2004.

SOARES, S. C. Os determinantes do desempenho escolar: uma análise para o estado de Pernambuco. Recife: Janeiro, 2010.

TODOS pela educação. 2011: < http://www.todospelaeducacao.org.br/> Acesso em: 21 de Fev. 2011. (Um Brasil para as crianças - Nota técnica. (S/ data.) 


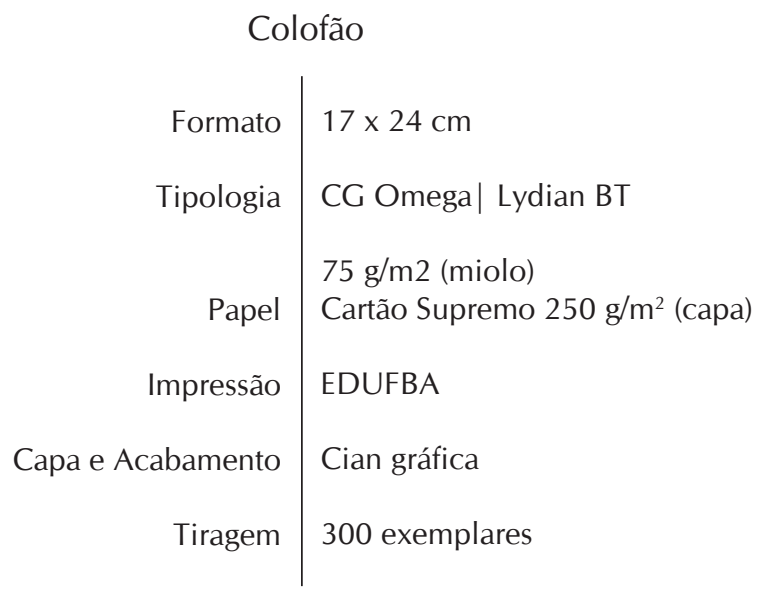

